\title{
Quantitative trait loci controlling kernel discoloration in barley (Hordeum vulgare L.)
}

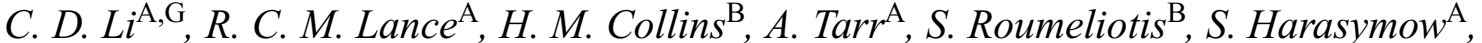

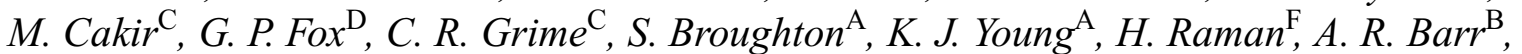 \\ D. B. Moody ${ }^{\mathrm{E}}$, and B. J. Read ${ }^{\mathrm{F}}$

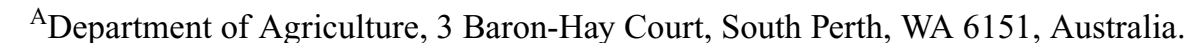 \\ ${ }^{\mathrm{B}}$ Department of Plant Science, University of Adelaide, Glen Osmond, SA 5064, Australia. \\ ${ }^{\mathrm{C}}$ School of Plant Biology (Plant Sciences), Faculty of Natural Resources and Agriculture, University of Western \\ Australia, Crawley, WA 6009, Australia. \\ ${ }^{\mathrm{D}}$ Department of Primary Industries, 13 Holberton Street, Toowoomba, Qld 4350, Australia. \\ ${ }^{\mathrm{E}}$ Department of Primary Industries, Victorian Institute for Dryland Agriculture, Private Bag 260, Horsham, Vic. \\ 3401, Australia. \\ ${ }^{\mathrm{F}}$ NSW Agriculture, Wagga Wagga Agricultural Institute, PMB, Wagga Wagga, NSW 2650, Australia. \\ ${ }^{\mathrm{G}}$ Corresponding author; email: cli@agric.wa.gov.au
}

\begin{abstract}
Barley kernel discoloration (KD) leads to substantial annual loss in value through downgrading and discounting of malting barley. $\mathrm{KD}$ is a difficult trait to introgress into elite varieties as it is controlled by multiple genes and strongly influenced by environment and maturity. As the first step towards marker assisted selection for KD tolerance, we mapped quantitative trait loci (QTLs) controlling KD measured by grain brightness [Minolta L; (Min L)], redness (Min a), and yellowness (Min b) in 7 barley populations. One to 3 QTLs were detected for grain brightness in various populations, and one QTL could account for $5-31 \%$ of the phenotypic variation. The QTL located around the centromere region of chromosome $2 \mathrm{H}$ was consistently detected in 6 of the 7 populations, explaining up to $28 \%$ of the phenotypic variation. In addition, QTLs for grain brightness were most frequently identified on chromosomes $3 \mathrm{H}$ and $7 \mathrm{H}$ in various populations. Australian varieties Galleon, Chebec, and Sloop contribute an allele to increase grain brightness on chromosome $7 \mathrm{H}$ in 3 different populations. A major gene effect was detected for grain redness. One QTL on chromosome $4 \mathrm{H}$ explained $54 \%$ of the phenotypic variation in the Sloop/Halcyon population, and was associated with the blue aleurone trait. A second QTL was detected on the long arm of chromosome $2 \mathrm{H}$ in 3 populations, accounting for $23-47 \%$ of the phenotypic variation. The major QTLs for grain yellowness were mapped on chromosomes $2 \mathrm{H}$ and $5 \mathrm{H}$. There were strong associations between the QTLs for heading date, grain brightness, and yellowness. The molecular markers linked with the major QTLs should be useful for marker assisted selection for KD.
\end{abstract}

Additional keywords: weather staining, grain quality, MAS.

\section{Introduction}

Barley kernel discoloration (KD), also referred to as weather staining, is caused by high humidity before harvest due to heavy rainfall and/or dews. Three main forms have been observed for KD. One common form is the caramelising of whole grain observed as the colour change from the light straw colour of bright grain to a deep yellow/brown coloured grain. The second form is black point or germ end staining characterised by black-brown discoloration at the embryo end of the grain. The extreme of the third form is where a greyish hue or distinctive spots appear on the grain as visible mould formation (Young and Loughman 2001), but it is rarely reported in the literature. Based on observations on 8 barley varieties in Queensland, the caramelising discoloration appears a far greater problem than black point in Australia (Williamson 1997). Whereas black point is measured by visual assessment, caramelising and mould staining can be assessed objectively using a colour metre or spectrophotometer. The staining effect can be measured in the black and white colour scale, with 0 being black and 100 being pure white, and the results expressed as 'L' (Lux units). For the caramelising effect, a colour space called Hue can be 
used. In this space, the scale is -60 for blue to +60 for yellow and reported as ' $b$ ' units.

In North America, KD is recognised as being associated with the important disease pathogens Bipolaris sorokiniana, Alternaria alternata, and Fusarium grannearum (Greaney and Machacek 1942; Crosier and Waters 1959; Anderson and Banttari 1976). Other leaf diseases also increase the KD incidence (Edney et al. 1998; Petr and Capouchova 2001). However, some recent studies indicated no correlation between KD symptoms and the presence of fungal mycelium (Jacobs and Rabie 1987; Basson et al. 1990). There is evidence to suggest that KD is due to abnormal phenol metabolism brought about by particular environmental conditions during grain filling and ripening (Cochrane 1994; Williamson 1997). Nevertheless, Young and Loughman (2001) found that barley varieties tolerant to KD had a consistently lower level of fungal ergosterol.

In contrast to the uncertainty of the cause of $\mathrm{KD}$, it is clear that $\mathrm{KD}$ is associated with grain yield loss and reduced malting quality (Anderson and Banttari 1976). Weather-stained barley had poor germination energy and vigor, tended towards prolonged post-harvest dormancy, and steeped at a faster rate. Malt from weather-stained barley tended to be lower extract, high wort colour, and high protein and modification. The beers had less desirable flavour and colour and high nitrogen (Malt Research Institute 1955). Thus, colour is an important consideration when purchasing barley. Discoloured barley is discounted in the market and severely discoloured barley is down-graded as feed. Australian malting barley producers lose around \$10 million each year due to malting barley being discounted or down-graded as a result of KD (Fox et al. 2001).

Weather is the most important factor for KD. The decisive effect on the occurrence of KD of malting barley is the rainy weather at the time of caryopsis formation and maturation (Young 1997, 1999; Petr and Capouchova 2001). Frequency of a longer period of rain was more important than amounts of precipitations. Young (1999) showed that the 3 p.m. relative humidity $(\mathrm{RH})$ could be used as an indicator for occurrence of KD in Western Australia. As the mean 3 p.m. RH reading increases from $50 \%$ to $60 \%$ for the period to harvest, the grain colour deteriorates rapidly. The effect of various agronomic management practices on KD has been investigated (Young 1999; Petr and Capouchova 2001), including fungicides, nitrogen, micro-nutrition, plant density, sowing date, harvesting technique, and soil type. Small improvements in grain kernel can be achieved in the short-term through attention to the finer details of agronomic packages. However, any one management practice is likely to have little effect on grain colour (Young 1999). The most effective method is to develop barley varieties with tolerance to $\mathrm{KD}$.

It has been demonstrated that genetic variability exists for KD tolerance among barley varieties (Miles et al. 1987;
Young 1997, 1999; Edney et al. 1998). Young (1997, 1999) found that most Australian barley varieties were susceptible to KD except Schooner barley. Tolerance sources to KD have been identified from the Japanese and Canadian germplasm. In the United States of America, two 6-row barleys (Chevron and CI-9538) showed high levels of tolerance to KD (Miles et al. 1987). Using these varieties as parents, distributions of the $F_{2}$ and $F_{3}$ populations for $\mathrm{KD}$ tolerance were nearly continuous and tended to follow a normal distribution (Wilcoxson et al. 1980; Miles et al. 1989). These results demonstrated that multiple genes controlled tolerance to KD with minor effect for each gene. The heritability of tolerance to $\mathrm{KD}$ in barley varied from $18 \%$ to $53 \%$ estimated from the $\mathrm{F}_{2}$ and $\mathrm{F}_{3}$ populations (Wilcoxson et al. 1980; Miles et al. 1989). Six cycles of crossing and selection were carried out, beginning in 1970, to incorporate KD tolerance genes into elite genetic backgrounds (Gebhardt et al. 1992). The level of tolerance was nearly recovered, but the new crossbreds failed to achieve acceptable kernel plumpness and malt extract level. The difficulty in recovering KD tolerance is partially due to the fact that degree of KD development was highly dependent on environmental conditions and partially due to the polygenic inheritance of KD tolerance, which would almost assure genetic linkage between genes for KD tolerance and the genes controlling grain yield, kernel plumpness, lodging reaction, and malting quality (Wilcoxson et al. 1980; Miles et al. 1989; Gebhardt et al. 1992). Marker-assisted selection could be used to overcome these difficulties if the quantitative trait loci (QTLs) controlling KD tolerance were identified. Our objective in the present study was to map the QTLs for KD tolerance from different sources as a precursor to developing marker assisted selection (MAS) breeding strategies.

\section{Materials and methods}

Seven populations were used to map the QTLs controlling KD measured with Min L (brightness), Min a (redness), and Min b (yellowness). Details of these populations are listed in Table 1. These populations were developed for the Grains Research and Development Corporation's National Barley Molecular Marker Program. The detailed maps of each population are available (this issue: Barr et al. $2003 a$, 2003b; Karakousis et al. 2003b; Read et al. 2003; also D. B. Moody et al., unpublished data). The variety Halcyon has the blue aleurone.

\section{Phenotyping for grain colour}

Weather is the most important factor for KD. The decisive effect on the occurrence of $\mathrm{KD}$ of malting barley is rainy weather at the time of caryopsis formation and maturation. Thus, the populations were planted in a high rainfall zone. The environmental conditions were highly favourable for development of KD in 2001. The Alexis/Sloop DH and Sloop/Alexis RIL populations were planted in Charlick Experiment Station, Strathalby, S. Aust., in 2000. The other populations were planted in high rainfall zones of Western Australia in 2001. There were 2 sites for the Arapiles/Franklin and VB9104/Dash populations: Esperance (ES) and Kendenup (KP). Sloop/Halcyon was planted in Mt Barker (WA) and Chebec/Harrington and Galleon/Haruna Nijo were 
Table 1. Barley populations used to map QTLs controlling kernel discoloration

\begin{tabular}{|c|c|c|c|c|}
\hline Populations & No. of DH & No. of markers & Sources ${ }^{\mathrm{A}}$ & Trial sites \\
\hline Alexis/Sloop-DH & 111 & 302 & UA & Charlick, SA \\
\hline Sloop/Alexis-RIL & 153 & 282 & UA & Charlick, SA \\
\hline Galleon/Haruna Nijo & 112 & 429 & UA & Esperance, WA \\
\hline Chebec/Harrington & 120 & 355 & UA & Esperance, WA \\
\hline Sloop/Halcyon & 166 & 204 & NSW & Mt Barker, WA \\
\hline Arapiles/Franklin & 168 & 229 & VIDA & Esperance \& Kendenup \\
\hline VB9104/Dash & 182 & 182 & VIDA & Esperance \& Kendenup \\
\hline
\end{tabular}

${ }^{A} U A$, University of Adelaide; NSW, NSW Agriculture; VIDA, Victorian Institute for Dryland Agriculture.

planted in Esperance. All trials were planted in a single replicate, randomised design with the parental varieties as random controls. Each line was planted in a 1 by $5 \mathrm{~m}$ plot and harvested from the middle $3 \mathrm{~m}$ except the Chebec/Harrington and Galleon/Haruna Nijo populations, which were grown in hill plots.

A 50 -g grain sample was used from each line to measure grain colour. Whole grain colour was measured with a Minolta CR-310 chromometer with a CR-A33e glass light projection tube and using a D65 light source setting. Grain brightness was recorded in CIE $(\mathrm{L}, \mathrm{a}, \mathrm{b})$ unit colour space. NIR grain brightness (CIE, L) calibration was developed on a FOSS-NIRSystems 6500 instrument in reflectance mode using WinISI software version 1.04 and MPLS regression. Min $\mathrm{L}$, $\mathrm{a}$, and $\mathrm{b}$ were used to measure grain brightness, redness, and yellowness, respectively.

\section{QTL analysis}

MapManager QTXb13 (Manly et al. 2001) software was used to map QTLs controlling KD tolerance. Both single point and interval mapping were used to detect QTLs. As multiple populations were used in the present study, a relatively low stringency was used to claim that a QTL existed for the target traits in order to compare the results from different populations. Simple regression analysis was first used to find the marker-trait associations under a low stringency $(P<0.05)$. The chromosomal regions showing significant linkage with the traits were further analysed using interval mapping. JMP (version: 4.0.2) software (SAS Institute 2000) was used for bi-variate analysis to test the relationships between grain brightness, redness, and yellowness.

\section{Results}

Variations of grain brightness, redness, and yellowness

In the 7 mapping populations, the difference in grain brightness between the 2 parents of each population varied from 0.5 to 4.0 Minolta L units (Table 2). The Japanese cultivar Haruna Nijo was 4 units brighter than Galleon. The parents Arapiles and Franklin showed little difference in both Esperance and Kendnup sites. On the other hand, VB9104 and Dash exhibited difference at different sites. In Kendenup, the 2 varieties were nearly the same, but showed 2.8 units difference at the Esperance site. Transgressive segregation was observed in each population (Table 2).

The variation in grain redness among the parents was small (Table 2). The largest difference was 1.6 units observed between Halcyon and Sloop. Again, transgressive segregation was demonstrated in all populations. Similar trends were also observed for grain yellowness (Table 2).

\section{QTLs controlling grain brightness}

One to three QTLs controlling grain brightness were detected in the various populations. Table 3 lists the chromosomal locations of QTLs, contribution of the QTL to phenotypic variation, closest linked marker, the probability of claiming a false QTL, and the parent contributing an allele to increased grain brightness. The detailed map for each population is published in this issue (Barr et al. 2003a, 2003b; Karakousis et al. 2003b; Read et al. 2003; also D. B. Moody et al., unpublished data).

Three QTLs were identified on chromosomes $2 \mathrm{H}, 3 \mathrm{H}$, and $7 \mathrm{H}$ for grain brightness in the Alexis/Sloop populations (Table 3). The QTLs were mapped to the same chromosomal locations in the DH and RIL populations. The Alexis alleles on chromosomes $2 \mathrm{H}$ and $3 \mathrm{H}$ increased grain brightness and the Sloop allele on chromosome $7 \mathrm{H}$ contributed to the increased grain brightness. The QTL on chromosome $2 \mathrm{H}$ accounted for $24-28 \%$ of the phenotypic variation, and the QTL on chromosome $7 \mathrm{H}$ contributed $14-18 \%$ variation in the 2 Alexis/Sloop populations. The QTL on chromosome $3 \mathrm{H}$ accounted for $31 \%$ of the phenotypic variation in the $\mathrm{DH}$ population, but only $13 \%$ in the RIL population. Three QTLs were identified in the Arapiles/Franklin population at both sites (Table 3). The QTLs were mapped to similar regions of chromosomes $2 \mathrm{H}, 3 \mathrm{H}$, and $7 \mathrm{H}$. The Franklin alleles on chromosomes $2 \mathrm{H}$ and $3 \mathrm{H}$ increased grain brightness, and Arapiles contributed a positive allele on chromosome $7 \mathrm{H}$. The QTLs detected from the Esperance site samples explained much more phenotypic variation than samples from the Kendenup site. Three QTLs for grain brightness were mapped on chromosomes $2 \mathrm{H}, 6 \mathrm{H}$, and $7 \mathrm{H}$ in the Chebec/Harrington population. Harrington contributed 2 positive alleles on chromosomes $2 \mathrm{H}$ and $6 \mathrm{H}$ and Chebec contributed a positive allele on chromosome 7H. Each QTL accounts for about the same proportion of the phenotypic variation. The QTL on chromosome $6 \mathrm{H}$ was not detected in any other population. One QTL was detected in samples from Esperance and Kendenup for the VB9104/Dash population, but located on chromosomes $2 \mathrm{H}$ and $5 \mathrm{H}$, respectively. Three QTLs were detected in the Galleon/Haruna Nijo population. Haruna Nijo contributed 2 
Table 2. Distribution of grain brightness (Min L), redness (Min a), and yellowness (Min b) in different barley mapping populations

\begin{tabular}{|c|c|c|c|c|}
\hline Populations & Maternal & Paternal & Population mean & Range \\
\hline \multicolumn{5}{|c|}{ Grain brightness, Min L } \\
\hline Alex/Sloop-DH & 61.00 & 58.21 & 59.31 & $55.88-64.01$ \\
\hline Alex/Sloop-RIL & 61.00 & 58.21 & 59.78 & $55.81-64.36$ \\
\hline Arapiles/Franklin (ES) & 58.10 & 58.60 & 58.40 & $55.12-61.19$ \\
\hline Arapiles/Franklin (KP) & 59.32 & 60.26 & 59.51 & $57.37-62.46$ \\
\hline Chebec/Harrington & 53.53 & 58.96 & 54.71 & $51.20-59.53$ \\
\hline Galleon/Haruna Nijo & 54.92 & 60.20 & 56.32 & $52.18-61.00$ \\
\hline Sloop/Halcyon & 59.81 & 58.60 & 59.90 & $57.16-63.28$ \\
\hline VB9104/Dash (ES) & 55.55 & 60.26 & 56.65 & $53.70-60.10$ \\
\hline VB9104/Dash (KP) & 57.26 & & 57.75 & $54.67-61.16$ \\
\hline \multicolumn{5}{|c|}{ Grain redness, Min a } \\
\hline Alex/Sloop-DH & 4.65 & 4.92 & 4.22 & $3.38-5.03$ \\
\hline Alex/Sloop-RIL & 4.65 & 4.92 & 4.36 & $3.44-5.19$ \\
\hline Arapiles/Franklin (ES) & 4.14 & 4.19 & 4.27 & $3.66-4.71$ \\
\hline Arapiles/Franklin (KP) & 3.87 & 4.16 & 4.07 & $3.74-4.44$ \\
\hline Chebec/Harrington & 5.77 & & 5.57 & $4.47-6.52$ \\
\hline Galleon/Haruna Nijo & 5.93 & 5.35 & 5.69 & $4.58-6.46$ \\
\hline Sloop/Halcyon & 2.27 & 3.85 & 3.07 & $1.80-4.40$ \\
\hline VB9104/Dash (ES) & 4.54 & 4.30 & 4.43 & $3.57-5.14$ \\
\hline VB9104/Dash (KP) & 4.33 & 3.91 & 4.01 & $3.39-4.67$ \\
\hline \multicolumn{5}{|c|}{ Grain yellowness, Min $b$} \\
\hline Alex/Sloop-DH & 23.93 & 24.80 & 23.77 & $22.03-24.98$ \\
\hline Alex/Sloop-RIL & 23.93 & 24.80 & 23.77 & $21.08-25.09$ \\
\hline Arapiles/Franklin (ES) & 21.54 & 22.51 & 21.77 & $18.97-23.47$ \\
\hline Arapiles/Franklin (KP) & 19.37 & 20.05 & 19.53 & $18.18-20.93$ \\
\hline Chebec/Harrington & 21.75 & & 21.81 & $19.22-25.06$ \\
\hline Galleon/Haruna Nijo & 22.49 & 21.52 & 22.69 & $20.29-25.96$ \\
\hline Sloop/Halcyon & 18.10 & 20.22 & 19.23 & $16.04-21.85$ \\
\hline VB9104/Dash (ES) & 19.51 & 22.05 & 20.86 & $18.56-23.97$ \\
\hline VB9104/Dash (KP) & 21.75 & 18.67 & 18.86 & $16.48-21.32$ \\
\hline
\end{tabular}

positive alleles on chromosome $2 \mathrm{H}$ and $3 \mathrm{H}$ and Galleon contributed the positive allele on chromosome $7 \mathrm{H}$. The QTL on chromosome $2 \mathrm{H}$ accounts for $21 \%$ of the phenotypic variation. Three QTLs were mapped in the Sloop/Halcyon population. Again, the chromosome $2 \mathrm{H}$ QTL explained the most variation. The QTL on chromosome $4 \mathrm{H}$ was not mapped in any other population.

\section{QTLs controlling grain redness}

Although the variation in grain redness among the parental varieties was small, QTLs with large effects on grain redness were detected in various populations (Table 3). A major QTL on chromosome $4 \mathrm{H}$ accounted for $54 \%$ of the phenotypic variation for grain redness in the Sloop/Halcyon population. Another QTL on the long arm of chromosome $2 \mathrm{H}$ explained $47 \%$ of the phenotypic variation for grain redness in the Alexis/Sloop population. The same QTL was also detected in the Chebec/Harrington population. One to two other minor QTLs for grain redness were found in various mapping populations (Table 3).

\section{QTLs controlling grain yellowness}

One to three QTLs were identified for grain yellowness in various populations (Table 3). The QTL on chromosome $2 \mathrm{H}$ was detected in all populations except in the Galleon/Haruna Nijo. Two QTLs on chromosomes $2 \mathrm{H}$ and $5 \mathrm{H}$ accounted for $18 \%$ and $24 \%$ of the phenotypic variation in the Alexis/Sloop DH population, but only a minor QTL was detected on chromosome $2 \mathrm{H}$ in the Sloop/Alexis RIL population. Two QTLs were identified at both sites for the Arapiles/Franklin population, but these QTLs were located on different chromosome regions. Similarly, one QTL was found at both sites for the VB9104/Dash population; these QTLs were located on chromosomes $2 \mathrm{H}$ and $5 \mathrm{H}$. One QTL on chromosome $2 \mathrm{H}$ in the Chebec/Harrington and one on chromosome $5 \mathrm{H}$ in the Galleon/Haruna Nijo population were mapped for grain yellowness. Three QTLs were detected on chromosomes $2 \mathrm{H}, 3 \mathrm{H}$, and $4 \mathrm{H}$ in the Sloop/Halcyon population. The QTL on chromosome $4 \mathrm{H}$, accounting for $31 \%$ of phenotypic variation, is also the major QTL for grain redness. 
Table 3. QTLs controlling barley grain colour brightness, Min a for barley colour redness, and Min b for barley colour yellow in the different populations

\begin{tabular}{|c|c|c|c|c|c|}
\hline Population & Chromosome & $R^{2}$ & Marker & $P$ & Positive allele \\
\hline \multicolumn{6}{|c|}{ Brightness } \\
\hline \multirow[t]{3}{*}{ Alexis/Sloop-DH } & $2 \mathrm{H}$ & 0.28 & EBmac684 & 0.00000 & Alexis \\
\hline & $3 \mathrm{H}$ & 0.31 & ABG4 & 0.00000 & Alexis \\
\hline & $7 \mathrm{H}$ & 0.18 & $\mathrm{LD}$ & 0.00001 & Sloop \\
\hline \multirow[t]{3}{*}{ Sloop/Alexis-RIL } & $2 \mathrm{H}$ & 0.24 & Ebmac684 & 0.00000 & Alexis \\
\hline & $3 \mathrm{H}$ & 0.13 & ABG4 & 0.00001 & Alexis \\
\hline & $7 \mathrm{H}$ & 0.14 & LD & 0.00003 & Sloop \\
\hline \multirow{3}{*}{ Arapiles/Franklin (ES) } & $2 \mathrm{H}$ & 0.14 & P13/M62-134 & 0.00000 & Franklin \\
\hline & $3 \mathrm{H}$ & 0.22 & $\mathrm{P} 14 / \mathrm{M} 49-210$ & 0.00000 & Franklin \\
\hline & $7 \mathrm{H}$ & 0.17 & Bmag110 & 0.00000 & Arapiles \\
\hline \multirow[t]{3}{*}{ Arapiles/Franklin (KP) } & $2 \mathrm{H}$ & 0.05 & $\mathrm{P} 14 / \mathrm{M} 61-154$ & 0.005 & Franklin \\
\hline & $3 \mathrm{H}$ & 0.07 & $\mathrm{P} 11 / \mathrm{M} 53-152$ & 0.0003 & Franklin \\
\hline & $7 \mathrm{H}$ & 0.04 & $\mathrm{P} 11 / \mathrm{M} 47-264$ & 0.002 & Arapiles \\
\hline \multirow[t]{3}{*}{ Chebec/Harrington } & $2 \mathrm{H}$ & 0.12 & Bmag125 & 0.0003 & Harrington \\
\hline & $6 \mathrm{H}$ & 0.12 & AWBMA36 & 0.0003 & Harrington \\
\hline & $7 \mathrm{H}$ & 0.15 & Bmag321 & 0.00004 & Chebec \\
\hline VB9104/Dash (ES) & $2 \mathrm{H}$ & 0.24 & HVM54 & 0.00000 & Dash \\
\hline VB9104/Dash (KP) & $5 \mathrm{H}$ & 0.18 & Bmag337 & 0.00000 & Dash \\
\hline \multirow[t]{3}{*}{ Galleon/Haruna Nijo } & $2 \mathrm{H}$ & 0.21 & Ebmac684 & 0.00002 & Haruna Nijo \\
\hline & $3 \mathrm{H}$ & 0.08 & AG/CAG408 & 0.007 & Haruna Nijo \\
\hline & $7 \mathrm{H}$ & 0.12 & AWBMA11 & 0.001 & Galleon \\
\hline \multirow[t]{3}{*}{ Sloop/Halcyon } & $2 \mathrm{H}$ & 0.18 & CDO474 & 0.00001 & Halcyon \\
\hline & $3 \mathrm{H}$ & 0.11 & $\mathrm{AG} / \mathrm{CGG} 3$ & 0.0006 & Halcyon \\
\hline & $4 \mathrm{H}$ & 0.09 & KsuA3 & 0.002 & Sloop \\
\hline \multicolumn{6}{|c|}{ Min a redness } \\
\hline \multirow[t]{2}{*}{ Alexis/Sloop (DH) } & $2 \mathrm{H}$ & 0.47 & AWBMA21 & 0.00000 & Alexis \\
\hline & $5 \mathrm{H}$ & 0.11 & Bmag222 & 0.00043 & Sloop \\
\hline \multirow[t]{3}{*}{ Sloop/Alexis (RIL) } & $2 \mathrm{H}$ & 0.33 & AWBMA21 & 0.00000 & Alexis \\
\hline & $5 \mathrm{H}$ & 0.06 & ABG712 & 0.006 & Sloop \\
\hline & $6 \mathrm{H}$ & 0.06 & GT/CGT151 & 0.004 & Sloop \\
\hline Arapiles/Franklin (ES) & $1 \mathrm{H}$ & 0.08 & $\mathrm{P} 11 / \mathrm{M} 47-302$ & 0.0002 & Franklin \\
\hline \multirow[t]{3}{*}{ Chebec/Harrington } & $2 \mathrm{H}$ & 0.23 & CDO665b & 0.00000 & Harrington \\
\hline & $4 \mathrm{H}$ & 0.08 & BCD351a & 0.003 & Harrington \\
\hline & $7 \mathrm{H}$ & 0.13 & HVCMA & 0.0001 & Chebec \\
\hline VB9104/Dash (KP) & $5 \mathrm{H}$ & 0.12 & Ebmac684 & 0.0004 & Dash \\
\hline \multirow[t]{2}{*}{ Galleon/Haruna Nijo } & $1 \mathrm{H}$ & 0.08 & $\mathrm{BCD} 453 \mathrm{c}$ & 0.007 & Haruna Nijo \\
\hline & $2 \mathrm{H}$ & 0.11 & AG/CAT131 & 0.001 & Galleon \\
\hline Sloop/Halcyon & $4 \mathrm{H}$ & 0.54 & AG/CAT4 & 0.00000 & Sloop \\
\hline \multicolumn{6}{|c|}{ Min b yellowness } \\
\hline \multirow[t]{2}{*}{ Alexis/Sloop (DH) } & $2 \mathrm{H}$ & 0.18 & Bmag125 & 0.00000 & Alexis \\
\hline & $5 \mathrm{H}$ & 0.24 & PSR637 & 0.00000 & Sloop \\
\hline Sloop/Alexis (RIL) & $2 \mathrm{H}$ & 0.07 & AWBMA21 & 0.001 & Alexis \\
\hline \multirow[t]{2}{*}{ Arapiles/Franklin (ES) } & $2 \mathrm{H}$ & 0.15 & P13/M62-134 & 0.00007 & Franklin \\
\hline & $3 \mathrm{H}$ & 0.14 & $\mathrm{P} 14 / \mathrm{M} 49-210$ & 0.00000 & Franklin \\
\hline \multirow[t]{2}{*}{ Arapiles/Franklin (KP) } & $3 \mathrm{H}$ & 0.07 & $\mathrm{P} 14 / \mathrm{M} 49-210$ & 0.002 & Franklin \\
\hline & $5 \mathrm{H}$ & 0.08 & $\mathrm{P} 11 / \mathrm{M} 52-303$ & 0.001 & Arapiles \\
\hline Chebec/Harrington & $2 \mathrm{H}$ & 0.20 & Bmag125 & 0.00000 & Harrington \\
\hline VB9104/Dash (ES) & $2 \mathrm{H}$ & 0.13 & HVM54 & 0.004 & VB9104 \\
\hline VB9104/Dash (KP) & $5 \mathrm{H}$ & 0.28 & Bmag337 & 0.0000 & VB9104 \\
\hline Galleon/Haruna Nijo & $5 \mathrm{H}$ & 0.23 & $\mathrm{ABC} 254$ & 0.00001 & Galleon \\
\hline \multirow[t]{3}{*}{ Sloop/Halcyon } & $2 \mathrm{H}$ & 0.10 & $\mathrm{CDO} 474$ & 0.002 & Halcyon \\
\hline & $3 \mathrm{H}$ & 0.12 & $\mathrm{AG} / \mathrm{CGT} 2$ & 0.002 & Halcyon \\
\hline & $4 \mathrm{H}$ & 0.31 & AG/CAT4 & 0.00000 & Sloop \\
\hline
\end{tabular}




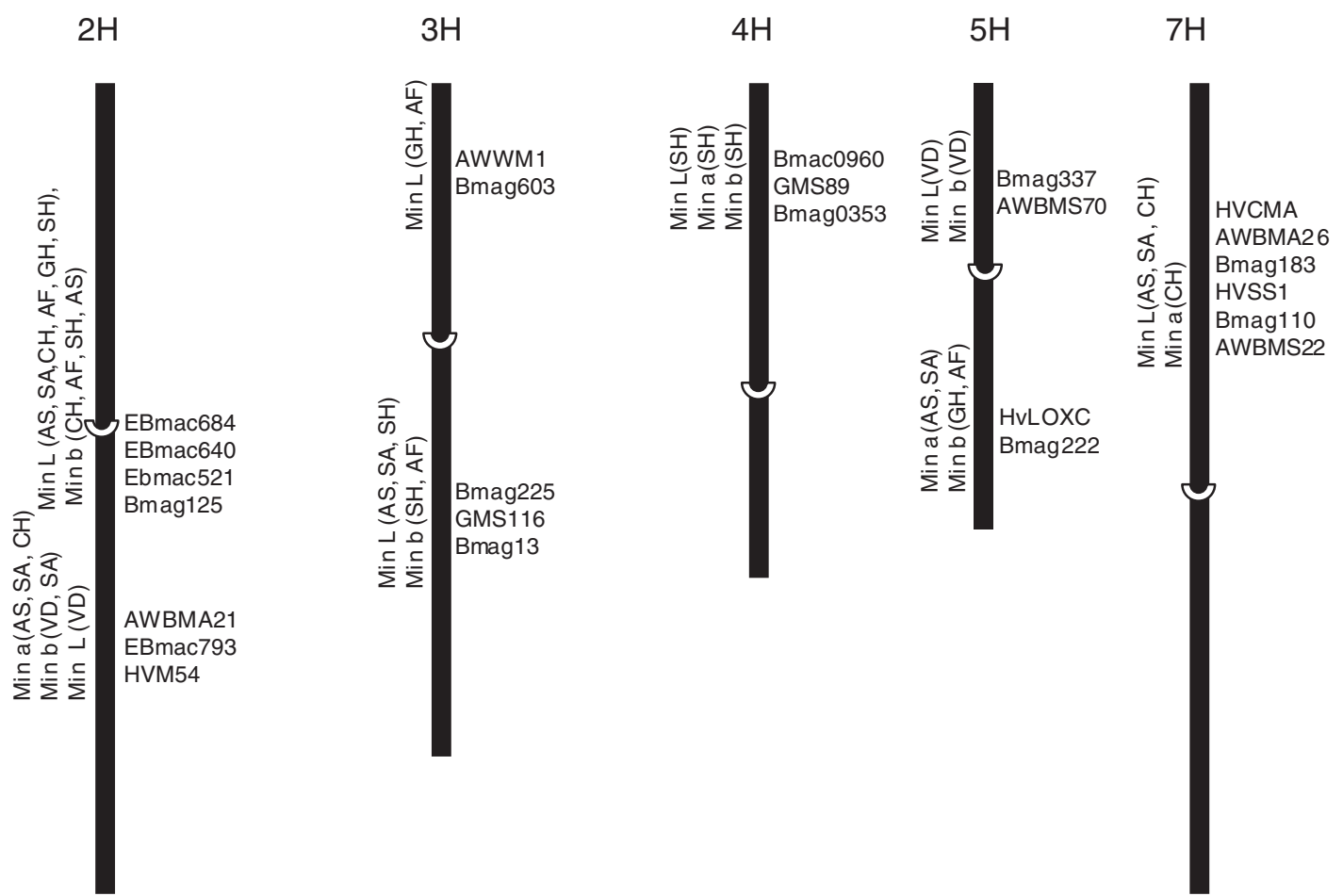

Fig. 1. Chromosomal locations of the QTLs controlling kernel discoloration, and the microsatellite markers associated with the QTLs. The assignment of a QTL to the chromosomal region was based on the barley consensus map (Karakousis et al. 2003a, this issue). The populations are indicated in parentheses (AS, Alexis/Sloop; SA, Sloop/Alexis; AF, Arapiles/Franklin; CH, Chebec/Harrington; VD, VB9104/Dash; GH, Galleon/Haruna Nijo; SH, Sloop/Halcyon).

Comparison of the chromosomal locations of the QTLs from different populations

One to three QTLs were identified in various populations for grain brightness, redness, and yellowness. The common markers mapped in these populations made it possible to compare the chromosomal locations of these QTLs. The chromosomal locations of these QTLs are summarised in Fig. 1, based on the consensus map (Karakousis et al. 2003a, this issue). One major QTL cluster for grain colour is located close to the centromere region of chromosome $2 \mathrm{H}$. The QTL controlling grain brightness was mapped in this region for Alexis/Sloop, Galleon/Haruna Nijo, Sloop/Halcyon, Arapiles/Franklin, and Chebec/Harrington populations, and explained up to $28 \%$ of the phenotypic variation for grain brightness. In addition, this region also controls grain yellowness in Chebec/Harrington, Arapiles/Franklin, and Sloop/Halcyon populations. There was a major QTL on the long arm of chromosome $2 \mathrm{H}$ controlling grain redness, which was mapped in the Alexis/Sloop DH and Sloop/Alexis RIL populations and Chebec/Harrington population. This QTL was located $\sim 20 \mathrm{cM}$ towards the telomere from the major QTL for grain brightness and explained up to $47 \%$ of the phenotypic variation. One QTL mapped in the VB9104/Dash population was also located on the long arm of chromosome $2 \mathrm{H}$ controlling both grain brightness and yellowness. In addition, one minor QTL for grain redness was mapped on the short arm of chromosome $2 \mathrm{H}$ in the Galleon/Haruna Nijo population.

There was one major QTL detected for grain brightness on the long arm of chromosome $3 \mathrm{H}$ in the Alexis/Sloop population. This region was also found to control grain brightness and yellowness in the Sloop/Halcyon population. One minor QTL for grain brightness was detected on the short arm of chromosome 3H in the Galleon/Haruna Nijo and Arapiles/Franklin populations.

One major QTL located on the short arm of chromosome $4 \mathrm{H}$ was mapped in the Sloop/Halcyon population controlling grain redness, yellowness, and brightness. This QTL was found to be associated with blue aleurone. One minor QTL was detected in this region for grain brightness in the Chebec/Harrington population.

Except for one major QTL mapped on chromosome 4H, major QTLs for grain yellowness were located on chromosomes $2 \mathrm{H}$ and $5 \mathrm{H}$. The QTL on chromosome $2 \mathrm{H}$ was located in a similar region of the QTL for brightness except in the VB9104/Dash population. The QTL on chromosome $5 \mathrm{H}$ was associated with a major QTL for heading date in the Galleon/Haruna Nijo population (Boyd et al. 2003, this issue). 
Table 4. Bi-variate analysis of Min $\mathrm{L}$, Min $\mathrm{a}$, and Min $\mathrm{b}$ in various populations Data in the table are $R^{2}$ between the two traits

\begin{tabular}{lccc}
\hline Populations & Min L-Min a & Min L-Min b & Min a-Min b \\
\hline Alexis/Sloop (DH) & 0.02 & 0.13 & 0.30 \\
Sloop/Alexis (RIL) & 0.01 & 0.13 & 0.29 \\
Galleon/Haruna Nijo & 0.01 & 0.12 & 0.07 \\
Chebec/Harrington & 0.08 & 0.22 & 0.34 \\
Sloop/Halcyon & 0.07 & 0.46 & 0.48 \\
Arapiles/Franklin (ES) & 0.01 & 0.59 & 0.01 \\
Arapiles/Franklin (KP) & 0.00 & 0.59 & 0.24 \\
VB9104/Dash (ES) & 0.01 & 0.57 & 0.01 \\
VB9104/Dash (KP) & 0.01 & 0.60 & 0.15 \\
\hline
\end{tabular}

A QTL for grain brightness on chromosome $7 \mathrm{H}$ was detected in the Alexis/Sloop, Arapiles/Franklin, Chebec/Harrington, and Galleon/Haruna Nijo populations. Except for the Galleon/Haruna Nijo population, the QTL for the other populations was located on the same region of the short arm. Interestingly, all of the Australian varieties studied contributed to increased grain brightness.

\section{Relationships between grain brightness, redness, and yellowness}

Min L, Min a, and Min b were used to measure barley grain brightness, redness, and yellowness, respectively. Bi-variate-fit analysis was used to calculate the contribution of each component to others with software JMP (version 4.0.2, SAS Institute 2000) (Table 4). Grain brightness and redness are independent. Min a contributed $0-8 \%$ of Min L variation. The contribution of Min $b$ to Min $L$ variation depends on the populations, varying from 12 to $60 \%$. For the populations with a large difference in Min L for the parental varieties, Min b contributed to less variation of Min $L$ in the populations of Galleon/Haruna Nijo, Chebec/Harrington, and Alexis/Sloop (Tables 2 and 4). In the populations of Arapiles/Franklin and VB9104/Dash, Min b accounts for $\sim 60 \%$ of the Min L variation. The relationship between Min $\mathrm{a}$ and Min $\mathrm{b}$ varied with both populations and experimental sites. Min a accounted for $\sim 30 \%$ variation of Min $b$ in the Alexis/Sloop and Chebec/Harrington populations. This could be due to linkage of the QTLs for Min b and Min a on chromosome 2H (Table 3). The QTL controlling blue aleurone on chromosome $4 \mathrm{H}$ affected Min a, Min b, and Min L. The same QTL could explain the relationships of Min a, Min b, and Min L in the Sloop/Halcyon population. Min a made a greater contribution to Min $b$ at the Kendenup site than at the Esperance site (ES) in both the VB9104/Dash and Arapiles/Franklin populations.

\section{Discussion}

Pena et al. (1999) reported mapping QTLs associated with $\mathrm{KD}$ in a barley population evaluated at 4 sites. They identified 11 QTLs associated with KD tolerance on all chromosomes except $1 \mathrm{H}$. Two major QTLs were mapped on chromosomes $5 \mathrm{H}$ and $6 \mathrm{H}$. There are 2 major differences between previous research and the present study. First, the KD in de la Pena et al.'s (1999) study was scored on the grain samples from either Fusarium head blight nurseries or $B$. sorokiniana-inoculated nurseries. The KD resulted from infection with $F$ graminearum or B. sorokiniana. A recent study showed that the major fungi species detected on weather-stained grain was A. alternata in Western Australia (Young and Loughman 2001). Thus, the fungi associated with KD are different. Second, de la Pena et al. (1999) used a 1-5 visual scale to measure KD based on the percentage of the discoloured grain and area of germ-end staining (this is also referred to as black point). We measured whole grain discoloration using a Minolta colour metre or a NIR spectrometer, calibrated to predict Minolta $\mathrm{L}$, a, and $\mathrm{b}$. Although significant germ-end staining will decrease the Min L reading, our preliminary research showed that these 2 measurements are genetically independent.

One QTL for grain brightness was consistently detected in all mapping populations except the VB9104/Dash population. This QTL was located around the centromere region of chromosome $2 \mathrm{H}$ and could explain up to $28 \%$ of grain brightness variation. A major QTL for heading date has also mapped in this region (Boyd et al. 2003). This raised the question of whether the coincident QTLs were due to linkage or pleiotropy. The positive QTL for grain brightness was from the late maturing parents in the Alexis/Sloop, Arapiles/Franklin, Chebec/Harrington, and Sloop/Halcyon populations. It is obvious that the late heading date contributed to grain brightness. However, Galleon headed 7 days later than Haruna Nijo and the DH lines with the Galleon allele at the QTL locus headed an average of 3.4 days later than lines with the Haruna Nijo allele in the Galleon/Haruna Nijo population. On the other hand, Haruna Nijo is 4.0 Minolta units brighter than Galleon, and the DH lines with the Haruna Nijo allele at the QTL locus are 1.5 units brighter than those with the Galleon allele. Thus, a QTL controlling grain brightness must be located close to the centromere region of chromosome $2 \mathrm{H}$. More detailed mapping is necessary to separate the heading date and grain brightness QTLs. Nevertheless, the microsatellite markers 
associated with this QTL could be used to monitor transferring the grain brightness from Haruna Nijo into elite breeding lines.

Two regions on chromosome $3 \mathrm{H}$ were associated with grain brightness. One QTL, mapped on the long arm of chromosome $3 \mathrm{H}$ in the Alexis/Sloop and Sloop/Halcyon populations, accounted for up to $31 \%$ of the phenotypic variation. Again, a major QTL for heading date was mapped in the same chromosomal region (Boyd et al. 2003). It is also noteworthy that the Ant-28 (a proanthocyanidin-less mutant) has been mapped to the same chromosomal region (Garvin et al. 1998).

A major gene effect was detected for grain redness. In the Sloop/Halcyon population, one QTL on chromosome $4 \mathrm{H}$ could explain $54 \%$ of the phenotypic variation. This locus is associated with the blue aleurone trait and was subsequently identified in the Min b data (Read et al. 2003). A second locus was detected on the long arm of chromosome $2 \mathrm{H}$ in 3 populations (Alexis/Sloop-DH, Sloop/Alexis-RIL, and Chebec/Harrington). This QTL accounted for $23-47 \%$ of the phenotypic variation and mapped to the same chromosomal region as morphological markers ant2 (anthocyanin-less) and Re2 (purple lemma, palea, and pericarp) (Søgaard and Wettstein-Knowles 1987). In the present study we showed that Min a is independent of Min L. Min L is the only measurement for grain colour used in the commercial barley grain receiving points in Western Australia. More research is needed to determine if grain redness has any effect on grain quality or malting quality before this trait is targetted with molecular markers in breeding programss.

Several factors have an important influence on the accuracy of QTL analysis (Asins 2002), including population size and experimental design. In the present study, 7 populations with over1000 lines were used to map the QTLs controlling KD. Due to the large number of lines used in this experiment, there was no replication in the trial. The following factors have been considered in designing this experiment: (1) weather is the most important factor for KD and agronomic management practice has little effect on grain colour (Young 1999), thus, variation of $\mathrm{KD}$ for a specific line would be expected to be low in one trial; (2) multiple populations could be used to validate the QTLs identified in any specific population; and (3) search for various $\mathrm{KD}$ tolerance resources/genes using multiple populations. The same QTL $(2 \mathrm{H})$ detected in multiple populations demonstrated that the strategy of mapping QTLs for KD is successful in the present study. This is further supported by the fact that the same 3 QTLs were detected for KD in the Alexis/Sloop-DH and Sloop/Alexis RIL populations. On the other hand, lack of replication in the trial increased the risk of detecting a false QTL and of over/under-estimating the QTL effect. More research is required to confirm the QTLs for KD, especially for the QTL detected only in one population.

\section{Acknowledgments}

The authors thank Ms Cathy Burchell and Ms Toni Cure for technical support. This project was supported by the GRDC and Western Malting Barley Council.

\section{References}

Anderson WH, Banttari EE (1976) The effect of Bipolaris sorokiniana on yield, kernel weight, and kernel discolouration in six-row spring barleys. Plant Disease Reporter 60, 754-758.

Asins MJ (2002) Present and future of quantitative trait locus analysis in plant breeding. Plant Breeding 121, 281-291. doi:10.1046/ J.1439-0523.2002.730285.X.

Barr AR, Jefferies SP, Broughton S, Chalmers KJ, Kretschmer JM, Boyd WJR, Collins HM, Roumeliotis S, Logue SJ, Coventry SJ, Moody DB, Read BJ, Poulsen D, Lance RCM, Platz GJ, Park RF, Panozzo JF, Karakousis A, Lim P, Verbyla AP, Eckermann PJ (2003a) Mapping and QTL analysis of the barley population Alexis $\times$ Sloop. Australian Journal of Agricultural Research 54, 1117-1123.

Barr AR, Karakousis A, Lance RCM, Logue SJ, Manning S, Chalmers KJ, Kretschmer JM, Boyd WJR, Collins HM, Roumeliotis S, Coventry SJ, Moody DB, Read BJ, Poulsen D, Li CD, Platz GJ, Inkerman PA, Panozzo JF, Cullis BR, Smith AB, Lim P, Langridge P (2003b) Mapping and QTL analysis of the barley population Chebec $\times$ Harrington. Australian Journal of Agricultural Research 54, 1125-1130.

Basson ABK, de Villiers OT, Rabie CJ (1990) Effect of black ends on quality characteristics of Clipper barley and malt. American Society of Brewing Chemists 48, 8-13.

Boyd WJR, Li CD, Grime CR, Cakir M, Potipibool S, Kaveeta L, Men S, Jalal Kamali MR, Barr AR, Moody DB, Lance RCM, Logue SJ, Read BJ (2003) Conventional and molecular genetic analysis of factors contributing to variation in the timing of heading among spring barley (Hordeum vulgare L.) genotypes grown over a mild winter growing season. Australian Journal of Agricultural Research 54, 1277-1301.

Cochrane MP (1994) Observations on the germ aleurone of barley. Phenol oxidase and peroxidase activity. Annals of Botany 73, 121-128. doi:10.1006/ANBO.1994.1014.

Crosier WF, Waters EC (1959) Fusarium graminearum and other fungi in seed stocks of small grains. Plant Disease Reporter $\mathbf{4 3}$, 1013-1015.

Edney MJ, Choo TM, Kong D, Ferguson T, Ho KM, May KW, Martin RA (1998) Kernel colour varies with cultivars and environments in barley. Canadian Journal of Plant Science 78, 217-222.

Fox G, Sulman M, Young K, Inkerman A (2001) Barley grain colour-objective measurement and biochemical studies. In 'Proceedings of the10th Australian Barley Technical Symposium'. Canberra. (ABT Ltd)

Garvin DF, Millergarvin JE, Viccars EA, Jacobsen JV, Brown AHD (1998) Identification of molecular markers linked to Ant-28-484, a mutation that eliminates proanthocyanidin production in barley seeds. Crop Science 38, 1250-1255.

Gebhardt DJ, Rasmusson DC, Wilcoxson RD (1992) Cyclic breeding used to incorporate kernel discolouration resistance into malting barley. Crop Science 32, 352-356.

Greaney FJ, Machacek JE (1942) Prevalence of seedbourne fungi on cereals in certain seed inspection districts of Canada. Scientific Agriculture 22, 419-437.

Jacobs B, Rabie CJ (1987) The correlation between mycelial presence and black point in barley. Phytophylactica 19, 77-81.

Karakousis A, Barr AR, Kretschmer JM, Manning S, Logue SJ, Roumeliotis S, Collins HM, Chalmers KJ, Li CD, Lance RCM, Langridge P (2003b) Mapping and QTL analysis of the barley 
population Galleon $\times$ Haruna Nijo. Australian Journal of Agricultural Research 54, 1131-1135.

Karakousis A, Gustafson JP, Chalmers KJ, Barr AR, Langridge P (2003a) A consensus map of barley integrating SSR, RFLP, and AFLP markers. Australian Journal of Agricultural Research 54, $1173-1185$.

Malt Research Institute (1955) A study of the influence of weathering on the suitability of barley for malting and brewing and annual reports 1951-52, 1952-53, 1953-54. Malting Research Institute Publication No. 12, pp. 2-16. (Malt Research Institute: Madison, WI)

Manly KF, Cudmore RH, Jr, Meer JM (2001) Map Manager QTX, cross-platform software for genetic mapping. Mammalian Genome 12, 930-932. doi:10.1007/S00335-001-1016-3.

Miles MR, Wilcoxson RD, Rasmusson DC (1989) Inheritance of resistance to kernel discolouration of barley. Plant Disease $\mathbf{7 3}$ 711-715.

Miles MR, Wilcoxson RD, Rasmusson DC, Wiersma J, Warnes D (1987) Influence of genotype and environment on kernel discolouration of Midwestern malting barley. Plant Disease 71, 500-504.

de la Pena RC, Smith KP, Capettini F, Muehlbauer GJ, Gallo-Meagher M, Dill-Macky R, Somers DA, Rasmusson DC (1999) Quantitative trait loci associated with resistance to Fusarium head blight and kernel discoloration in barley. Theoretical and Applied Genetics $\mathbf{9 9}$, 561-569. doi:10.1007/S001220051269.

Petr J, Capouchova I (2001) Causes of the occurrence of malting barley kernel discolouration. Monatsschrift für Brauwissenschaft 5, 104-113.
Read BJ, Raman H, McMichael G, Chalmers KJ, Ablett GA, Platz GJ, Raman R, Genger RK, Boyd WJR, Li CD, Grime CR, Park RF, Wallwork H, Prangnell R, Lance RCM (2003) Mapping and QTL analysis of the barley population Sloop $\times$ Halcyon. Australian Journal of Agricultural Research 54, 1145-1153.

SAS Institute (2000) 'JMP—Statistical discovery software. Version 4.' (SAS Institute: Cary, NC)

Søgaard B, Wettstein-Knowles P (1987) Barley: genes and chromosomes. Carlsberg Research Communications 52, 123-196.

Wilcoxson RD, Rasmusson DC, Banttari EE, Johnson DA (1980) Feasibility of selecting for resistance to kernel discolouration in barley. Plant Disease 64, 928-930.

Williamson PM (1997) Black point in wheat and its relevance to barley. In 'Proceedings of 8th Australian Barley Technical Symposium'. Gold Coast. pp. 2.11.5-2.11.8. (ABT Ltd)

Young KJ (1997) Weather staining of barley in Western Australia. In 'Proceedings of the 8th Australian Barley Technical Symposium'. Gold Coast. pp. 2.11-2.19. (ABT Ltd)

Young KJ (1999) Grain colour in barley: agronomic and genetic solutions. In 'Proceedings of the 9th Australian Barley Technical Symposium'. Melbourne. pp. 2.15.1-2.15.7. (ABT Ltd)

Young KJ, Loughman R (2001) Fungal associations with weather stained barley in Western Australia. In 'Proceedings 10th Australian Barley Technical Symposium'. Canberra. (ABT Ltd)

Manuscript received 2 January 2003, accepted 4 July 2003 